\title{
A COMPARATIVE STUDY OF NUMBER AND POSITION OF PAPILLARY MUSCLES AND CLINICAL SIGNIFICANCE
}

\author{
Soumya S Muraleedharan *1, Sailaja K ${ }^{2}$.
}

${ }^{* 1}$ MBBS, MD, Lecturer, Dept of Anatomy, Govt. Medical College, Kozhikode, Kerala, India.

${ }^{2}$ MBBS, MD, Additional Professor, Dept of Anatomy, Govt Medical College, Manjeri, Kerala, India.

\section{ABSTRACT}

Introduction: Papillary muscles are the conical muscle masses project into the cavity of ventricle and are inserted into the valve cusps by chordae tendinae. They prevent the cusps from being forced back into the atrium during ventricular contraction. Their number and positions are highly variable. An anomalous papillary muscle can act as an ectopic foci. Hence these variations should be assessed before any operative intervention on the valve. Present study aim to analyse these variations in detail.

Materials and Methods:_This is a descriptive observational study to analyse the variations in number and position of papillary muscles in ventricles of 100 adult human hearts ranging in age from 17 to 80 years obtained from autopsy specimens. The methodology used was the dissection method according to standard autopsy techniques. The data obtained were quantified as frequencies (in \%).

Results: Of the 100 hearts studied, the right ventricle consisted of the usual three groups of papillary muscles in $84 \%$ of hearts whereas the remaining $16 \%$ of hearts had only two groups (rudimentary SPMs). The left ventricle consisted of two groups of papillary muscles in $73 \%$ of hearts ; three groups in $23 \%$; four groups in $4 \%$ and none of the hearts contained single papillary muscle. Regarding the positions, the right ventricle had APMs in anterobasal position, the PPMs in posterobasal position and SPMs was located close to ventricular septum and no extra group of papillary muscles were found. In left ventricle, $73 \%$ of hearts had APMs and PPMs in anterolateral and posteromedial positions respectively, whereas in $27 \%$ ( $23 \%$ and $4 \%$ ) hearts, the extra group of papillary muscles (third group and fourth group) were interlinked to PPMs and was situated in posterolateral position.

Conclusion: These findings suggest that the variations in number and positions of papillary muscles should be anticipated before any operative intervention on the valvular apparatus.

KEY WORDS: Anterior Papillary Muscle, Posterior Papillary Muscle, Septal Papillary Muscle.

Address for Correspondence: Dr. Soumya S Muraleedharan,MBBS, MD, Lecturer, Dept of Anatomy, Govt. Medical College, Kozhikode, Kerala, India. E-Mail: soumyasmuraleedharan@gmail.com

Access this Article online

Quick Response code

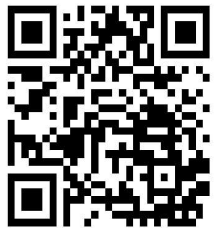

DOI: $10.16965 /$ ijar.2018.394

Journal Information

International Journal of Anatomy and Research

ICV for 2016 ISSN (E) 2321-4287 | ISSN (P) 2321-8967

90.30 https://www.ijmhr.org/ijar.htm

DOI-Prefix: https://dx.doi.org/10.16965/ijar

Article Information

Received: 24 Sep 2018

Peer Review: 25 Sep 2018

Revised: 29 Sep 2018
Accepted: 01 Nov 2018

Published (O): 05 Dec 2018

Published (P): 05 Dec 2018

\section{INTRODUCTION}

Papillary muscles are the conical muscle masses project into the cavity of ventricle and are inserted into the margins and ventricular surfaces of two adjacent cusps of atrioventricular valves by tendinous strands (chordae tendinae). On contraction, they draw the margins of the adjacent cusps together and prevent the cusps from being forced back into the atrium as the intraventricular pressure rises which in turn increases the efficiency of the ventricular contraction and permits the atrium to fill completely while the ventricle is contracting. The number and positions of papillary muscles can vary significantly which are important in anticipating various subvalvular techniques during valve repair. 
Papillary muscle rupture is an uncommon life threatening complication of acute myocardial infarction usually 2-7 days after an acute infarct. Without surgical intervention, mortality is estimated to be $50 \%$ in the first 24 hours and could reach $90 \%$ by one week. An increase in number and size of papillary muscles in the left ventricle can cause Left Ventricular Outflow Tract (LVOT) obstruction. An anomalous papillary muscle can be an ectopic foci in the heart as right branch of conducting system blends with it. Knowledge of these variations would be useful in surgical techniques like papillotomy and commissurotomy in rheumatic lesions, leaflet resection in advanced myxomatous lesions, excision of infective vegetation, transfer and rotation of leaflet segments in traumatic conditions and in correction of functional Tricuspid Regurgitation.

Aim: Present study aim to analyse the variations in number and position of papillary muscles of right and left ventricles in detail.

\section{MATERIALS AND METHODS}

This is a descriptive observational study to analyse the variations in number and position of papillary muscles in ventricles of 100 adult human hearts (70 males and 30 females) ranging in age from 17 to 80 years obtained from autopsy specimens, Dept of Forensic Medicine, Govt. Medical College, Kozhikode (with permission).

Inclusion criteria: Adult human hearts obtained with no gross anomalies or no pathological changes were included.

Exclusion criteria: Hearts with ventricular wall thickness of more than $15 \mathrm{~mm}$ were excluded.

Materials used: Gloves, Dissection box, Brain knife, Vernier caliper, Camera

Methodology: Dissection method [1] Dissection was performed according to standard autopsy techniques.

(1) Using scissors, the initial cut was made between the ostia of both vena cavae to the right atrial appendage. Right atrium was opened and cleaned with water to remove any blood clots so as to visualise the tricuspid orifice from above. Then we opened the right ventricle with a V-shaped cut along its right margin and across the anterior wall of the right ventricle.

(2) The left atrium was opened between the superior pulmonary veins. Then we extended the cut to inferior pulmonary veins and to the left atrial appendage. A knife was passed between the two leaflets of mitral valve so as to pierce the apex and sliced upward parallel to the interventricular septum along the left heart border to open the cavity of left ventricle. Any residual clots were removed with water.

(3) The papillary muscles of both ventricles were inspected and noted the number of groups and positions.

Photographs were taken to document the important findings. The results obtained were tabulated in groups and expressed as percentage (\%).

\section{RESULTS}

Number of groups of papillary muscles: The two major papillary muscles in the right ventricle are located in anterior and posterior positions. The third, smaller muscle has a medial position together with several smaller and variable muscles attached to the ventricular septum. The two muscles supporting the leaflets of mitral valve are the anterolateral and posteromedial groups. Of these, the anterolateral papillary muscles arise from the sternocostal mural myocardium and the posteromedial group from the diaphragmatic region.

Table 1: Number of groups of papillary muscles in ventricles.

\begin{tabular}{|c|c|c|}
\hline $\begin{array}{c}\text { No. of groups } \\
\text { of PM }\end{array}$ & $\begin{array}{c}\text { RV } \\
\text { (frequency in \%) }\end{array}$ & $\begin{array}{c}\text { LV } \\
\text { (frequency in \%) }\end{array}$ \\
\hline 1 & 0 & 0 \\
\hline 2 & 16 & 73 \\
\hline 3 & 84 & 23 \\
\hline 4 & 0 & 4 \\
\hline
\end{tabular}

Of the 100 hearts analysed, the right ventricle consisted of three groups of papillary muscles (APM, PPM and SPM) in 84 hearts (84\%) (Fig 1) where as the remaining 16 hearts (16\%) had only rudimentary septal papillary muscles. (Fig 2).

The left ventricle consisted of two groups of papillary muscles in 73 hearts (73\%) (Fig 3) and three groups in 23 hearts (23\%) (Fig 4). In $4 \%$ of hearts, we observed four groups of papillary muscles (Fig 5) whereas none of the hearts contained single papillary muscle. 
Position of papillary muscles: The relative positions of papillary muscles could be assessed better in their functional state by standard transthoracic two dimensional echocardiography (than in autopsy study).

In Right ventricle, of the $84 \%$ hearts with three groups of papillary muscles, all the anterior group of muscles was located anterobasally and posterior group of muscles was situated posterobasally in the normal anatomical position of heart. Another group of small papillary muscles near to interventricular septum were considered as septal group of muscles which were positioned more medially. However, in 16\% of hearts, septal group of papillary muscles were not seen in our study.

In Left ventricle, of the $73 \%$ of hearts with two groups of papillary muscles, the anterior group of muscles was situated anterolaterally and posterior group of muscles was located posteromedially in the normal anatomical position of the heart. In $23 \%$ of hearts, in addition to that, we found another distinct group of muscles interlinked to the normal posterior group by narrow muscular strands which were considered as the third group of muscles. In the remaining $4 \%$ of hearts, we noticed one more muscle group in the same pattern attached to the posterior cusp of the valve which were considered as the fourth muscle group. Both of these muscle groups were positioned posterolaterally when we hold the heart in the anatomical position.

Table 2: The relative positions of papillary muscles in ventricles of heart.

\begin{tabular}{|c|c|c|c|c|c|}
\hline Ventricle & APM & PPM & SPM & \multicolumn{2}{|c|}{ EPM } \\
\hline Right & Anterobasal & Posterobasal & Septal & - & - \\
\hline Left & Anterolateral & Posteromedial & & $\begin{array}{c}\text { Posterolateral } \\
\text { (third group) }\end{array}$ & $\begin{array}{c}\text { Posterolateral } \\
\text { (fourth group) }\end{array}$ \\
\hline
\end{tabular}

Fig 1: Three Groups of Papillary muscles in Right ventricle.

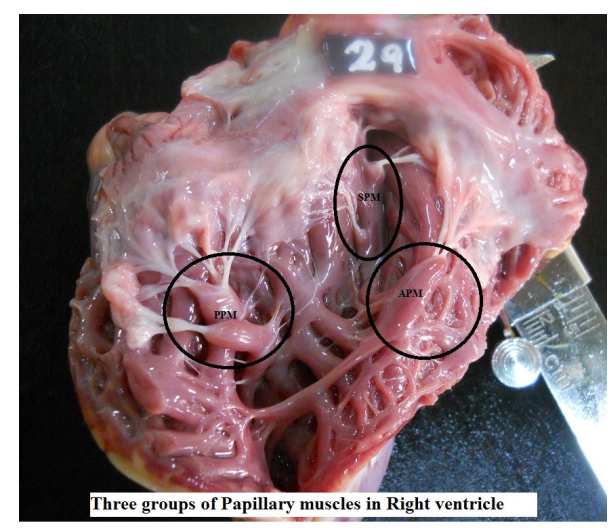

Fig 2: Well developed Anterior (APM) and Posterior (PPM) Papillary muscles and rudimentary septal Papillary muscle (rSPM) in the Right ventricle.

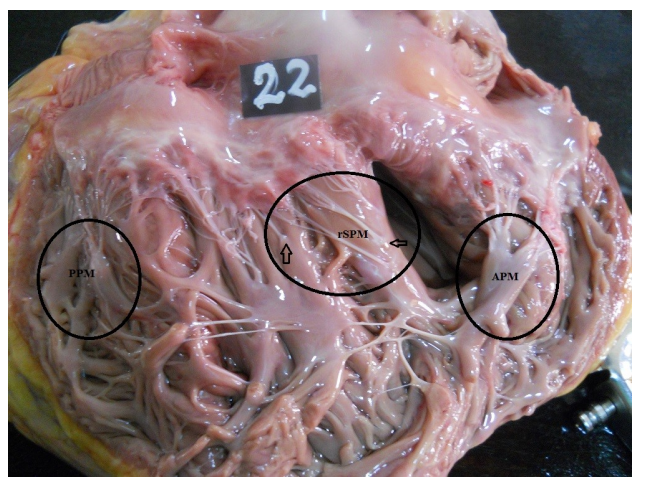

Fig 3: Well developed Anterior (APM) and Posterior (PPM) Papillary muscles and rudimentary septal Papillary muscle (rSPM) in the Right ventricle.

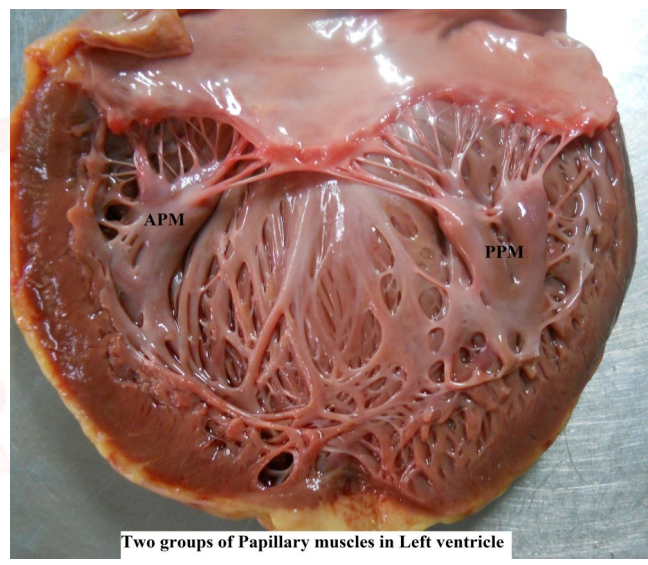

Fig 4: Three Groups of Papillary muscles in the Left ventricle.

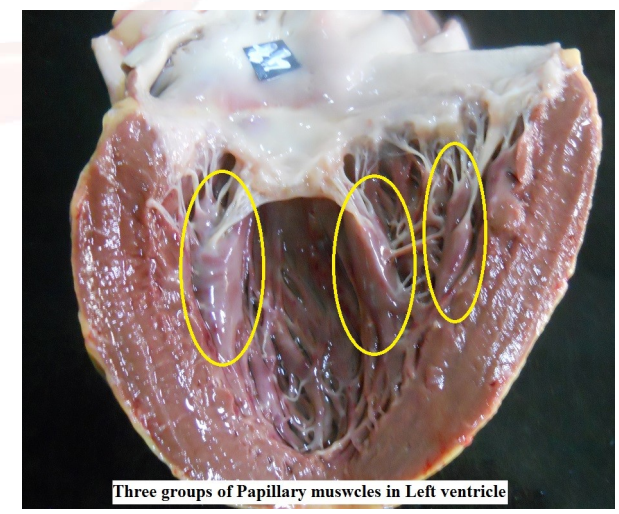

Fig 5: Four Groups of Papillary muscles in the Left ventricle.

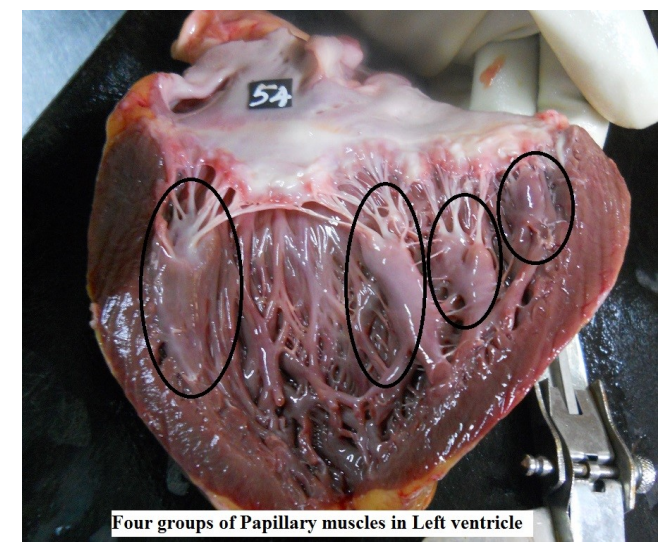




\section{DISCUSSION}

An increase in number and size of papillary muscles could precipitate ventricular outflow tract obstruction and severe valvular regurgitation. Therefore it is important to look for the number of groups of papillary muscles.

Number of groups of papillary muscles in Right Ventricle: Nigri et al [2] in 2001 observed 3 groups of papillary muscles in $78.5 \%$ of cases and 2 groups in $21.5 \%$ in a sample of 79 normal human hearts.

In 2003, Jezyk et al [3] noticed 3 groups of papillary muscles in $70 \%$ of hearts and in the remaining $30 \%$, they observed 4 groups of muscles in a sample of 111 normal human hearts.

Ekin Aktas et al [4] in 2004 examined the papillary muscles in 200 autopsy cases and noticed 3 groups of muscles in 170 hearts (85\%) and 2 groups of muscles in the remaining $15 \%$.

Another study in 100 normal human hearts by Loukas et al [5] in 2009 observed 3 groups of papillary muscles in $58 \%$ of cases and in the remaining $42 \%$, they noticed 4 groups of muscles.

In 2014, Harsha B R et al [6] noted 3 groups of papillary muscles in $73(76 \%)$ and 2 groups in $23(24 \%)$ in a sample of 96 normal human hearts. In the present study, we observed the classical 3 groups of papillary muscles (APM, PPM and SPM) in majority (84\%) of cases and 2 groups of muscles (rudimentary or absent SPM) in the remaining $16 \%$. None of the hearts contained a single group of muscle. Present study closely resembled to that of Ekin Aktas et al (2004) [4]. Table 3: Comparison of Number of groups of papillary muscles in Right ventricle from various studies.

\begin{tabular}{|c|c|c|c|c|c|c|c|}
\hline \multirow{2}{*}{$\begin{array}{c}\text { Year of } \\
\text { study }\end{array}$} & \multirow{2}{*}{ Author } & \multirow{2}{*}{ Population } & \multirow{2}{*}{$\begin{array}{c}\text { Sample } \\
\text { size }\end{array}$} & & \multicolumn{5}{|c|}{$\begin{array}{c}\text { No of groups of PMs in RV } \\
\text { (Incidence in \%) }\end{array}$} \\
\cline { 5 - 10 } & & & & 1 & 2 & 3 & 4 \\
\hline 2001 & Nigri et al[2] & American & 79 & 0 & 21.5 & 78.5 & - \\
\hline 2003 & Jezyk et al[3] & Italian & 111 & 0 & - & 70 & 30 \\
\hline 2004 & E Akts et al[4] & Arabian & 200 & 0 & 15 & 85 & - \\
\hline 2009 & Loukas et al[5] & Italian & 100 & 0 & - & 58 & 42 \\
\hline 2014 & Harsha B R et al[6] & Indian & 96 & 0 & 24 & 76 & - \\
\hline \multicolumn{2}{|c|}{ Present study } & Indian & 100 & 0 & 16 & 84 & _ \\
\hline
\end{tabular}

Number of groups of papillary muscles in Left Ventricle: In 1962, Carney E K et al [7] reported about occurrence of accessory papillary muscles in the left ventricle and its association with congenital Mitral Regurgitation in 9 patients.

In 1963, Shone and Seller et al [8] observed that occurrence of a single papillary muscle as the most common congenital anomaly affecting the left ventricular papillary muscles. They noted that all the mitral chordae were attached to this single muscle (parachute mitral valve) and was usually associated with other malformations including a supramitral valve ring, diffuse subaortic stenosis or coarctation of the aorta.

William Robert et al [9] in 1972 noticed single papillary muscle in the left ventricle in 20 cases of the 47 patients studied.

Victor S, Nayak V M et al [10] observed 2 groups of papillary muscles in 84 hearts $(84 \%)$ and 3 groups of muscles in the remaining $16 \%$ in a sample of 100 normal human hearts in the year 1995.

Alper Ucak et al [11] in 2010 noted an accessory papillary muscle in the left ventricle with its chordae in the subaortic area, precipitating outflow tract obstruction and severe aortic insufficiency in a young adult.

Kuo-Tzu Sung et al [12] in 2014 observed hypertrophied anterolateral and posteromedial papillary muscles together with a large, third accessory papillary muscle causing mid cavity obstruction in the left ventricle in an adult.

In 2013 S A Gunnal et al [13] studied papillary muscles of mitral valve complex in 116 human cadaveric hearts and noted 2 groups of papillary muscles in 50 (43.11\%) hearts, three groups in 37 (31.9\%), four groups in 25 (21.55\%) and only two papillary muscles ('classical') in 4 (3.44\%) hearts.

A cadaveric study of papillary muscles of left ventricle in 50 formalin fixed adult human heartsin 2014 by Hosapatna M et al [14] cited 2 groups of papillary muscles in $46(92 \%)$ hearts and in 4 (8\%) hearts, they observed 3 groups of muscles ${ }^{63}$. Another case reported by Kotaro Oe et al [15] in 2015 noticed abnormally high number of papillary muscles in the left ventricle of an adult (accessory papillary muscles) causing left ventricular outflow tract obstruction. In the present study, we noted 2 groups of papillary muscles in 73 (73\%) hearts, 3 groups 
in $23(23 \%), 4$ groups in $4(4 \%)$ of cases in a sample of 100 normal human hearts. None of them contained a single group of papillary muscle or classical type (only two papillary muscles).

Table 4: Comparison of Number of groups of papillary muscles in Left ventricle from various studies.

\begin{tabular}{|c|c|c|c|c|c|c|c|c|}
\hline \multirow{2}{*}{$\begin{array}{c}\text { Year of } \\
\text { study }\end{array}$} & Author & \multirow{2}{*}{ Population } & \multirow{2}{*}{$\begin{array}{c}\text { Sample } \\
\text { size }\end{array}$} & \multicolumn{5}{|c|}{ No of groups of PMs in LV (Incidence in } \\
\cline { 5 - 10 } & & & & 1 & 2 & 3 & 4 & 'classical' \\
\hline 1972 & William Robert et al[9] & British & 47 & 20 & - & - & - & \\
\hline 1995 & Victor Set al[10] & Indian & 100 & - & 84 & 16 & - & - \\
\hline 2013 & SA Gunnal et al[13] & Indian & 116 & - & 43.11 & 31.9 & 21.55 & 3.44 \\
\hline 2014 & Hosapatna M et al[14] & Indian & 50 & - & 92 & 8 & - & \\
\hline & Present Study & Indian & 100 & - & 73 & 23 & 4 & - \\
\hline
\end{tabular}

Congenital absence of papillary muscles: Hashimoto K et al [16] in 2001 reported a case of congenital mitral regurgitation in a young patient occurred due to the absence of the anterolateral papillary muscle and the corresponding marginal chordae. They corrected this abnormality (by anterolateral commissural annuloplasty and by insertion of an artificial chordae to prevent prolapse of the anterior leaflet) with good postoperative outcome.

In 2010, W B Christopher et al [17] reported a case of congenital absence of posteromedial papillary muscle and the corresponding chordal apparatus to the anterior leaflet of mitral valve causing prolapse of anterior leaflet and severe Mitral Regurgitation in a 6 year old child (visualised by echocardiography).

In 2010, Fumiaki Shikata et al [18] noted a case of hypoplastic anterior papillary muscle with absent chordae resulting in isolated congenital Tricuspid Regurgitation (TR) in an adult.

Anomalies in position of papillary muscle: In 1969, Castaneda and Anderson et al [19] observed abnormally large and malpositioned papillary muscles in the left ventricle causing narrowing of orifice of the mitral valve in young adults.

Maron B J, Njshimura R A et al [20] evaluated two patients in 1997, who had an anomalous papillary muscle inserting directly into the anterior mitral leaflet, producing significant midcavity obstruction. This anomaly was challenging to identify with echocardiography because the exaggerated anterior displacement of hypertrophied papillary muscles closely resembled the systolic anterior motion of mitral valve or congenital malformation of mitral valve apparatus. This should always be anticipated before any operative intervention (Standard Myotomy / Myectomy). Kotaro Oe et al [15] in 2015 reported a case of left ventricular outflow tract obstruction caused by two anteriorly displaced papillary muscles in the left ventricle.

Teo E P et al [21] in the same year noticed anterior displacement of papillary muscles along with degenerative leaflet changes on mitral valve and aberrant chordal attachments in patients with left ventricular outflow tract obstruction.

In our study, the right ventricle consisted of the usual three groupsof papillary muscles in majority of hearts (84\%). Of these, all the anterior group of muscles was situated anterobasally and posterior group of muscles was located posterobasally in the normal anatomical position of heart. This is because of the fact that the anterior and posterior cusps of tricuspid valve are more nearly horizontal than vertical. Another group of muscles situated close to interventricular septum were considered as the septal group which were positioned more medially. In the remaining $16 \%$ of hearts, septal group of papillary muscles were not developed in our study. In Left ventricle, majority of hearts (73\%) had two groups of papillary muscles, of which the anterior group of muscles was situated anterolaterally and posterior group of muscles was located posteromedially in the normal anatomical position of the heart. In $23 \%$ of hearts, in addition to that, we found another distinct muscle group interlinked to the normal posterior group by narrow muscular strands which were considered as the third group of muscles. In the remaining $4 \%$ of hearts, we noted one more muscle group in the same pattern attached to the posterior cusp of the valve which were considered as the fourth muscle group. Both of these muscle groups were positioned posterolaterally when we hold the heart in the anatomical position.

\section{CONCLUSION}

In the present study, the Right ventricle consisted of the usual 3 groups of muscles in $84 \%$ of hearts and 2 groups in the remaining $16 \%$. 
The Left ventricle had the usual 2 groups of muscles in $73 \%$ of hearts, 3 groups in $23 \%$ and 4 groups in the remaining $4 \%$ of hearts. Regarding the positions of papillary muscles, the right ventricle had APMs in anterobasal position, the PPMs in posterobasal position and SPMs was located close to ventricular septum and no extra group of papillary muscles were found. In left ventricle, $73 \%$ of hearts had APMs and PPMs in anterolateral and posteromedial positions respectively, whereas in $27 \%(23 \%$ and $4 \%)$ hearts, the extra group of papillary muscles (third group and fourth group) were interlinked to PPMs and was situated in posterolateral position.

These variations should be anticipated in patients who present with symptoms suggestive of decreased cardiac output (while performing standard two dimensional transthoracic echocardiography) before planning any surgical interventions on the valvular apparatus. An anomalous papillary muscle can act as an ectopic foci in heart that can precipitate conduction blockade. This should kept in mind before doing any ablation procedure.

\section{ABBREVIATIONS}

RV - Right Ventricle

LV - Left Ventricle

PM - Papillary Muscle

APM - Anterior Papillary Muscle

PPM - Posterior Papillary Muscle

SPM - Septal Papillary Muscle

rSPM - rudimentary Septal Papillary Muscle

EPM - Extra Papillary Muscle.

\section{ACKNOWLEDGEMENTS}

The author thanks all the faculties and staff members of Department of Forensic Medicine, Govt. Medical College, Kozhikode for providing me with materials and valuable suggestions during my work.

\section{Conflicts of Interests: None}

\section{REFERENCES}

[1]. Ludwig J. Autopsy manual Cardiovascular System. Handbook of Autopsy Practice, $3^{\text {rd }}$ Edition. 2002:4548.
[2]. Nigri G R, Di Dio L J, Baptista C A. Papillary muscles and tendinous cords of the right ventricle of the human heart: morphological characteristics. Surg.Radiol Anat. 2001;23(1):45-49.

[3]. Jezyk D., Jerzemowski J., Grzybiak M. Provision of tricuspid valve leaflets by septal papillary muscles in the right ventricle of human and other mammal hearts. Folia Morphol. (Warsz) 2003;62:309-311.

[4]. Ekin O. Aktas MD, Figen Govsa MD, Aytac Kocak MD, Bahar Boydak MD, Ismail C. Yavuz MD. Variations in the papillary muscles of normal tricuspid valve and their clinical relevance in medicolegal autopsies. Saudi Med J 2004;25(9):1176-1185.

[5]. Loukas M, Tubbs R.S, Louis R.G. Jr, Apaydin N, Bartczak A, Huseng V, Alsaiegh N, Fudalej M. An endoscopic and anatomical approach to the septal papillary muscle of the conus. Surg. Radiol. Anat. 2009;31:701-706.

[6]. Dr. Harsha B. R \& Dr. Dakshayani K. R. Morphometric Study on Septal Papillary Muscles of Human Tricuspid Valve. Global Journal of Medical research (USA) 2014;14(1):1.

[7]. Carney E K, Braunwald E, Roberts W C, Aygen M, MoR Row A G. Congenital mitral regurgitation: Clinical, hemodynamic and angiocardiographic findings in nine patients. Amer. J Med 1962;33:223.

[8]. Shone JD, Seller RD, Anderson RC, Adams P, Lillehei CW, Edwards JE. The developmental complex of "parachute mitral valve. Supravalvular ring of left atrium, subaortic stenosis, and coaretation of aorta. Amer J Cardiol. 1963;11:714.

[9]. William C Roberts MD , Lawrece S Cohen MD. Left Ventricular Papillary Muscles : Description of the normal and a survey of conditions causing them to be abnormal. Circulation, 1972;XLVI:138-154.

[10]. Victor S, Nayak V M. Variations in the papillary muscles of the normal mitral valve and their surgical relevance. J Card Surg.1995 Sep;10(5):597-607.

[11]. Alper Ucak M.D, Burak Onan M.D, Ýbrahim Alp M.D, Ahmet Turan Yýlmaz M.D. Accessory mitral papillary muscle causing severe aortic insufficiency. Türk Kardiyol Dern Aro - Arch Turk Soc Cardiol 2010;38(8):564-567.

[12]. Kuo-Tzu Sung, Chun-Ho Yun, Charles Jia-Yin Hou and Chung-Lieh Hung. Solitary accessory and papillary muscle hypertrophy manifested as dynamic midwall obstruction and symptomatic heart failure: diagnostic feasibility by multi-modality imaging. BMC Cardiovascular Disorders 2014;14:34.

[13]. Sandhya Arvind Gunnal , Rajendra Namdeo Wabale, Mujeebuddin Samsamuddin Farooqui. Morphological variations of papillary muscles in the mitral valve complex in human cadaveric hearts. Singapore Med J 2013;54(1):44-48.

[14]. Mamatha Hosapatna, Anne D Souza, Aswin Das M, Supriya, Vrinda Hari Ankolekar, Antony Sylvan D Souza. Morphology of Papillary Muscles in Human Adults: A Cadaveric study. Ibnosina J Med BS 2014; 6(4):168-172. 
[15]. Kotaro Oe MD, Tsutomu Araki MD, FJCC, Miho Ohira MD, Tetsuo Konno MD, FJCC, Masakazu Yamagishi MD, FJCC. Left ventricular outflow tract obstruction with abnormal papillary muscles. Journal of Cardiology Cases . 2015 Feb;11(2):69-72.

[16]. Hashimoto K, Oshiumi M, Takakura H, Sasaki T, Onoguchi K. Congenital mitral regurgitation fromabsence of the anterolateral papillary muscle. Thorac Surg 2001;72:1386-1387.

[17]. Christopher W. Baird MD, A. Resai Bengur MD, Andrew Bensky MD, and Larry T. Watts, MD, Charlotte, NC. Congenital absence of posteromedial papillary muscle and anterior mitral leaflet chordae: The use of three-dimensional echocardiography and approach in complex pediatric mitral valve disease. The Journal of Thoracic and Cardiovascular Surgery 2010;139(4).

[18]. Fumiaki Shikata, Mitsugi Nagashima, Kazuhisa Nishimura, Fuminaga Suetsugu, Kanji Kawachi . Repair of congenitally absent chordae in a Tricuspid valve leaflet with hypoplastic papillary muscle using artificial chordae. J Card Surg 2010 Nov 29;25(6):737-739.
[19]. Castaneda A R, Anderson R C, Edwards J E: Congenital mitral stenosis resulting from anomalous arcade and obstructing papillary muscles: Report of correction by use of ball valve prosthesis. Amer J Cardiol. 1969;24:237.

[20]. Barry J. Maron, MD; Rick A. Nishimura, MD; Gordon K. Danielson, MD. Pitfalls in Clinical Recognition and a Novel Operative Approach for Hypertrophic Cardiomyopathy With Severe Outflow Obstruction Due to Anomalous Papillary Muscle. Circulation 1998; 98:2505-2508.

[21]. Teo E P, Teoh J G, Hung J. Mitral valve and papillary muscle abnormalities in hypertrophic obstructive cardiomyopathy. Curr Opin Cardiol. 2015 Sep ;30(5):475-482.

How to cite this article:

Soumya S Muraleedharan, Sailaja K. A COMPARATIVE STUDY OF NUMBER AND POSITION OF PAPILLARY MUSCLES AND CLINICAL SIGNIFICANCE. Int J Anat Res 2018;6(4.3):6002-6008. DOI: 10.16965/ijar.2018.394 